\title{
NBSIR 87-3656
}

\section{Experimental Plan for Investigation of Lighting and HVAC Interactions}

Stephen J. Treado

U.S. DEPARTMENT OF COMMERCE

National Bureau of Standards

National Engineering Laboratory

Center for Building Technology

Building Physics Division

Gaithersburg, MD 20899

October 1987

Issued February 1988

Prepared for:

U.S. Department of Energy 



\section{EXPERIMENTAL PLAN FOR}

INVESTIGATION OF LIGHTING AND

HVAC INTERACTIONS

Stephen J. Treado

U.S. DEPARTMENT OF COMMERCE

National Bureau of Standards

National Engineering Laboratory

Center for Building Technology

Building Physics Division

Gaithersburg, MD 20899

October 1987

Issued February 1988

Prepared for:

U.S. Department of Energy

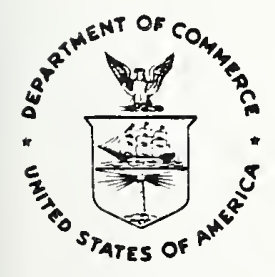

U.S. DEPARTMENT OF COMMERCE, C. William Verity, Secretary NATIONAL BUREAU OF STANDARDS, Ernest Ambler, Director 
This report describes the experimental plan for the investigation of the interaction of lighting and HVAC systems, including the purpose and scope of the research, the test facility and instrumentation system, and the data collection and analysis procedures. The research focuses on the relationship between lighting system design and performance, room design; and HVAC system design for typical office-type construction.

A test facility will be constructed and instrumented to enable variation of lighting, room and HVAC design. Testing will be performed for various configurations. The results will be used to develop design guidelines and modeling procedures, particularly for incorporation into building energy analysis computer programs.

Keywords :

building energy performance; cooling load; lighting; thermal performance; weighting factors 


\section{FORWARD}

This report is an initial report in a series of reports by the National Bureau of Standards on the interaction of lighting an HVAC system. The NBS research was supported by the U.S. Department of Energy (DoE) under contract No. DE-A1D1-76 PR06010, Task 008, Mod. No. 56.

\section{ACKNOWLEDGMENTS}

The author wishes to acknowledge the active encouragement and support provided by the Department of Energy technical representatives, Mr. Robert Boettner, Jean Boulin, Carol Gardner and John Ryan.

\section{DISCLAIMER}

Any commercial products or tradenames mentioned in this report are included for informational purposes only and do not constitute any endorsement or recommendation by the National Bureau of Standards. 


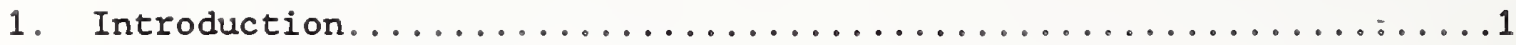

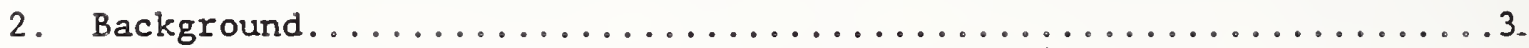

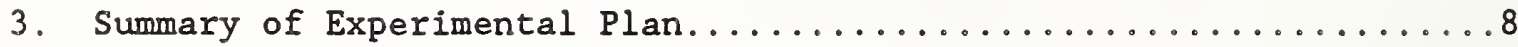

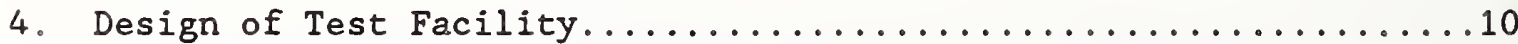

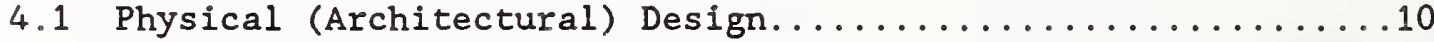

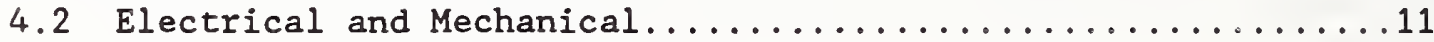

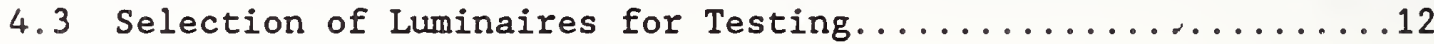

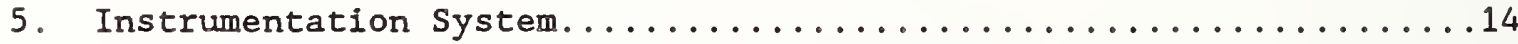

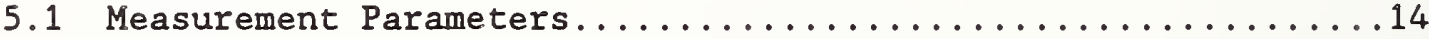

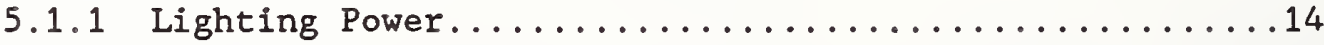

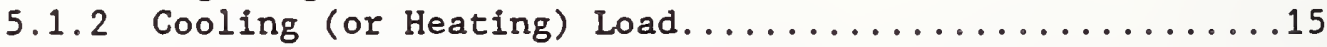

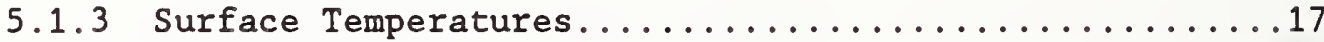

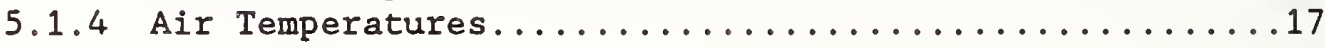

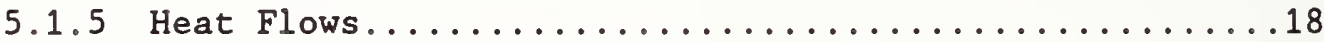

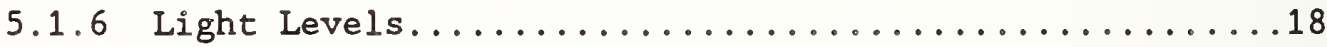

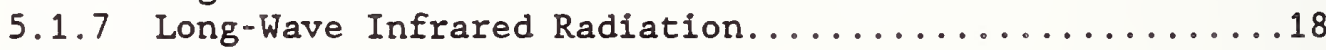

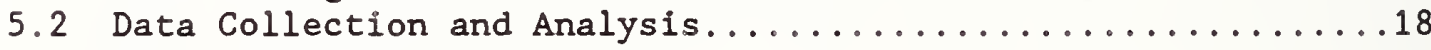

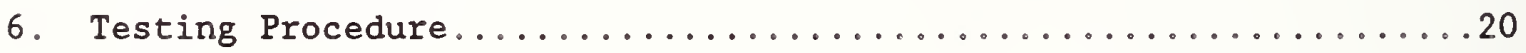

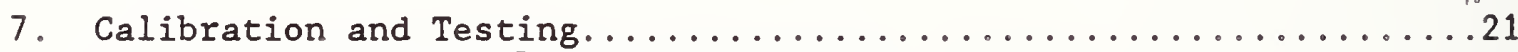

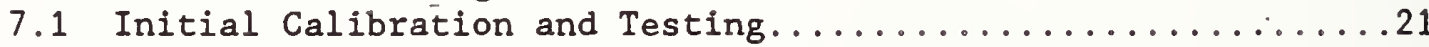

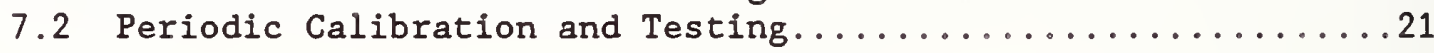

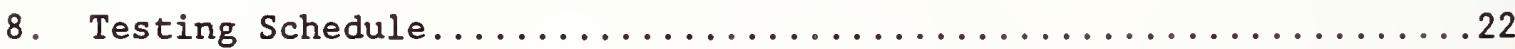

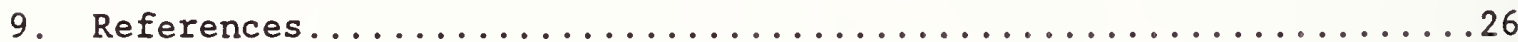




\section{List of Tables}

Table 1. Description of the Six Luminaire Types..............13

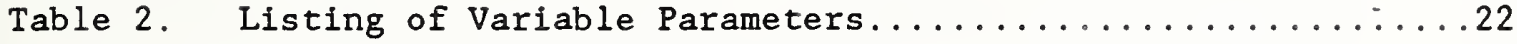

Table 3. Schedule for Sensitivity Testing................... 3

Table 4. Schedule for Primary Testing.................... 24 


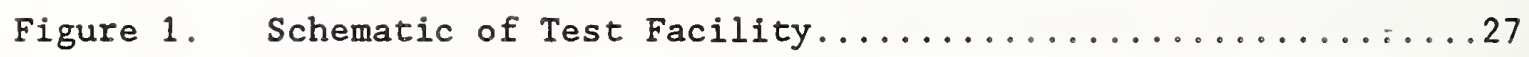

Figure 2. Control room roof supports HVAC equipment............28

Figure 3. Test room slabs and steel support frame.............29

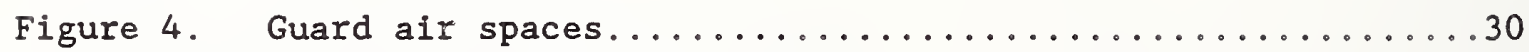

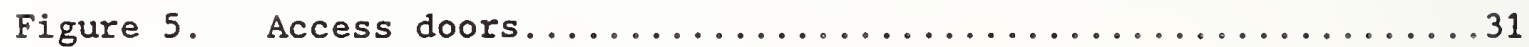

Figure 6. Air Handling Unit \#1, test room and \#2, Guard Air.......32

Figure 7. Air Handling Unit $\# 3$, lower plenun...................

Figure 8. Supply and return ductwork for test room............. 34

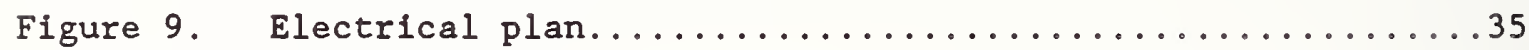

Figure 10. Schematic of guard air temperature control...........36

Figure 11. Locations of surface temperature measurements.........37

Figure 12. Air temperature measurement locations...............

Figure 13. Locations of heat flux transducers.................... 


\section{INTRODUCTION}

This project is a combined, cooperative effort between the U.S. Department of Energy (DoE), the Electric Power Research Institute (EPRI), Dubin-Bloom Associates and Ross \& Baruzzini, Inc. (DB-RB); and the National Bureau of Standards (NBS).

The purpose of this research is to obtain the interaction characteristics of HVAC and lighting systems by studying the heat distribution characteristics of various lighting systems in typical room thermal environments. This is to assist both HVAC and lighting engineers by developing a database for detailed lighting heat transfer calculations, to enable analysis of the components of lighting heat transfer, and to evaluate the influence of wall and floor construction and HVAC design on lighting and cooling/heating loads.

The research specifically will examine the relationships among electrical power input, lighting output and cooling load, and the methods used to determine the air conditioning and heating load impacts of lighting, so that design professionals can more accurately quantify the heat from lighting. Improvements in the quantification of the distribution of energy from lighting (e.g., to plenum and occupied space) promotes innovation in controlling and directing lighting heat. The project team will present innovative methods for rejecting or using the heat from lights.

Experimental testing will present.. a platform whereby HVAC engineers and lighting designers can work together to consider the complex interaction between HVAC and lighting systems for various lighting systems in typical room thermal environments. As a result, illumination engineers will have a quantitative evaluation of the influence of wall floor, ceiling and fenestration construction and HVAC design on lighting and cooling/heating loads.

The test facility will be designed to allow various testing configurations and measurements, including the following studies to be carried out:

- the thermal interaction between light fixtures, room components, and HVAC systems; and

- the exchange of energy by conduction, convection, and radiation exchange within the room;

- the performance of the air-conditioning terminal units and other heating and cooling devices.

- heat transfer by conduction, convection, and radiation through building envelope sections exposed to a variety of weather conditions; 
The research program consists of three basic elements. These are:

1) detailed full-scale measurements of lighting and HVAC system performance

2) the detailed modeling of test facility

3 ) the generation of simplified models, algorithms and guidelines 
ASHRAE studies indicate that electric energy consumption in commercial buildings can range from 25 to $50 \%$ of total building energy use. Since the early $1970^{\prime}$ 's efforts have been made to reduce the lighting energy consumption without reducing its illumination performance, such as the development of high efficiency ballasts, high efficacy light tubes, and the use of daylighting.

The heat dissipated by luminaires is a major element of the year-round cooling load in the building interior zone. It also provides a major portion of the necessary winter heating energy in the perimeter zone. Unless the fixture is adequately cooled, decreases in luminous efficacy and shortened life result. Both air and water cooled fixtures are available; however, a recommended practice for evaluating performance is available only for the air cooled type. Since it dominates the market place at present, the air cooled type will be the focus of this project.

Current cooling procedures can involve the introduction of as much as $50 \mathrm{CFM}$ of room air or return air into the luminaire. The efficiency with which the removed heat is applied to the winter heating requirement, and the effect on cooling loads, is influenced by the design of the lighting and HVAC systems. An optimization design method is needed whereby net annual energy consumption, illumination performance and peak load performance are considered. An important element of such an optimization design procedure is an improved understanding of the heat transfer from the lighting system.

Hour-by-hour simulation of energy consumption requires consideration of the fact that heat from the lighting fixture is dissipated into the air before it adds cooling load in the summer or reduces the heating requirements in winter.

The heat emitted by the lighting fixture is dissipated in the following manner:

1. Part of the heat is released by convection into the air that either surrounds the fixture or is circulated through it by means of connections to the ventilation system.

2. If the heated air leaving the lighting fixture is not vented into the ceiling plenum space, and eventually to the central HVAC system, it tends to increase the room air temperature. Depending upon the mode of the heating and cooling operation at the time of lighting, this increased room temperature either activates the cooling thermostat or deactivates the heating thermostat. In other words, the heat convected away from the lighting fixture becomes an instantaneous cooling load. 
3. Part of the heat emitted from lighting fixtures is radiated out to the surface that "see" the light sources.

The heat radiated to the room surfaces in turn can be reflected back onto other surfaces, where it can be conducted away from the room, convected back into the room air or stored within the component. The process is complex and requires detailed heat balance calculations.

If the outdoor temperature is constant, and if there are no other heat sources in the room, the cooling load $Q$ approaches the steady-state $Q^{\infty}$, which is equal to the total power supplied to the lighting fixture $P$ minus the envelope heat loss, or:

$$
Q^{\infty}=\mathrm{P}-\left(\Sigma \mathrm{U}_{\mathrm{k}} \mathrm{A}_{\mathrm{k}} \quad \Delta \mathrm{T}_{\mathrm{k}}+\mathrm{G}(\Delta \mathrm{T})\right.
$$

where:

$$
\begin{aligned}
& U_{k} \text { and } A_{k} \text { : overall heat transfer coefficient and area } \\
& \text { of the } k \text {-th surfaces that are exposed to } \\
& \text { outside environment, } \\
& \Delta \mathrm{T}_{\mathrm{k}} \text { : temperature difference across the } \mathrm{k} \text {-th } \\
& \text { surface, } \\
& \text { G: the room air leakage, } \\
& C \text { : specific heat of air, and } \\
& \Delta \mathrm{T} \text { : temperature difference between indoor and } \\
& \text { outdoor air. }
\end{aligned}
$$

The time required for $Q$ to approach the steady-state value $Q_{\infty}$ depends upon several factors, such as:

1. air flow rate through or near the lighting fixture,

2. thermal storage characteristics of the surfaces that are irradiated by the light,

3. heat conduction characteristics of the surfaces,

4. radiation heat exchange characteristics of the lighting fixture,

5. outdoor temperature, and

6. power density of the lighting systems (watt/sq. ft. of floor area).

If, for example, the heat receiving surfaces are highly conductive and have a large thermal capacity, it will take many hours before $Q_{\infty}$ is reached. On the other hand, if the heat receiving surfaces are all adiabatic, $Q$ becomes $Q_{\infty}$ instantly.

The exact treatment of the heat transfer process associated with the lighting fixture is extremely complex. It involves transient and three-dimensional convection, conduction, and radiation heat transfer processes surrounding the lighting fixture. An extensiveliterature search on this and related subjects was conducted by $\mathrm{H}$. Ball. Among all of the previous work in this area, the most notable contributions were made by Sowell, Mitalas/Kimura, and $\mathrm{H}$. 
Ball. While Sowell treated the radiative heat transfer effects in detail [1], Ball et al. [2] provided detailed and comprehensive analysis of the transient heat conduction phenomenon. Kimura and Stephenson [3], on the other hand, developed a simplified heat transfer model based on the experimental observation that the trend for $Q$ to become $Q^{\infty}$ is a simple exponential function.

For example, if there is no envelope heat loss, the relationship between $\mathrm{Q}$ and $\mathrm{P}$ may be approximated by:

$$
Q(t)=P\left[1-C_{1} \exp -\left(C_{2} t\right)\right]
$$

Empirical constants such as $C_{1}$ and $C_{2}$ can readily be determined from measurements by monitoring the change of $Q(t)$ with respect to time in a test room. In this expression $C_{2}$ represents the rate of reduction for the quantity $P-Q$ with respect to time and $1-C_{1}$ represents the instantaneous cooling load fraction of $P$ when the lights are suddenly turned on. $C_{1}$ can be determined by the intercept of the $Q$ vs time $t$ plot at $t-0$ as follows:

$$
C_{1}=\frac{P-Q(0)}{P}
$$

While equation (1) is appropriate for predicting the change of $Q$ with respect to time as long as $P$ remains constant, Mitalas and Kimura developed an autoregressive relation between time varying $Q$ and. $P$ by introducing three conduction transfer functions, $V_{1}, V_{2}$, and $w$ as follows:

$$
Q_{1}=v_{1} P_{t}-\Delta+V_{2} P_{t}-2 \Delta+W Q_{t}-\Delta
$$

where $P_{t-\Delta}$ and $P_{t-2} \Delta$ indicate power inputs to the lighting fixture at time $t^{-\Delta}$ and $t^{-} 2^{\Delta}$, while $Q_{t}$ and $Q_{t-\Delta t}$ are the cooling loads at time $t$ and $t^{-\Delta,}$ respectively. $\quad v_{1}, v_{2}$, and $w$ are the transfer functions and can be calculated using $C_{1}$ and $C_{2}$ by the following equations :

$$
\begin{aligned}
& \mathrm{w}=\exp \left(-\mathrm{C}_{2}{ }^{\Delta}\right. \\
& \cdot \mathrm{v}_{1}=1-\exp \left(1 \mathrm{nC}-\mathrm{C}_{2}{ }^{\Delta}\right) \\
& \mathrm{v}_{2}=1-\mathrm{v}_{1}-\mathrm{w}
\end{aligned}
$$

Three sets of these transfer functions were generated by Mitalas and Kimura by their calorimetric tests [4-7] for typical offices having "light", "medium", and "heavy" thermal mass and are presented in the 1977 ASHRAE Handbook of Fundamentals.

Ball extended the Mitalas/Kimura sets of conduction transfer functions by using a computer simulated Q-P relationship [8] . Having those conduction transfer functions available, one can now determine the cooling load due to lighting while the power input to the luminaire is changing continuously, in hourly steps. 
In spite of these notable achievements of previous workers, there are, however, several shortcomings to the current ASHRAE transfer function approach:

1. They cannot be extrapolated for specific types of buildings which may not be similar to the test configurations that were used for the development of the current data. All of the current measured data were obtained for an interior office space with no exterior walls.

2. The ASHRAE transfer functions are not suitable for detailed heat balance calculations. This is especially true when light heat dissipation is a function of the luminaire temperature, as is the case for some modern luminaires [9], and when the time increment for the dynamic simulation is other than one hour, as is the case for control simulation.

3. The current transfer function data are unable to account for energy losses through the building envelope, especially during the winter. The conduction transfer function approach inherently assumes that all the heat dissipated by the luminaire will eventually be picked up by the room air.

This assumption is the result of another more fundamental assumption that the instantaneous ratio between the radiative heat dissipation, Rand the power input to the luminaire, $P$ is constant

$$
\text { or } C_{1}=\frac{R}{P}=\frac{P-Q_{0}}{P}
$$

regardless of the environmental condition.

The heat dissipation process of a luminaire having the power input $P$ can be expressed as radiative heat loss $R$ and convective heat loss C such, that:

$$
P=R+C
$$

On the other hand $\mathrm{R}$ and $\mathrm{C}$ can be expressed by:

$$
\begin{aligned}
& \mathrm{R}=\operatorname{hr} A\left(\mathrm{~T}_{\mathrm{B}}-\mathrm{T}_{\mathrm{MRT}}\right) \\
& \mathrm{C}=\operatorname{hc} A\left(\mathrm{~T}_{\mathrm{B}}-\mathrm{T}_{\mathrm{a}}\right)
\end{aligned}
$$

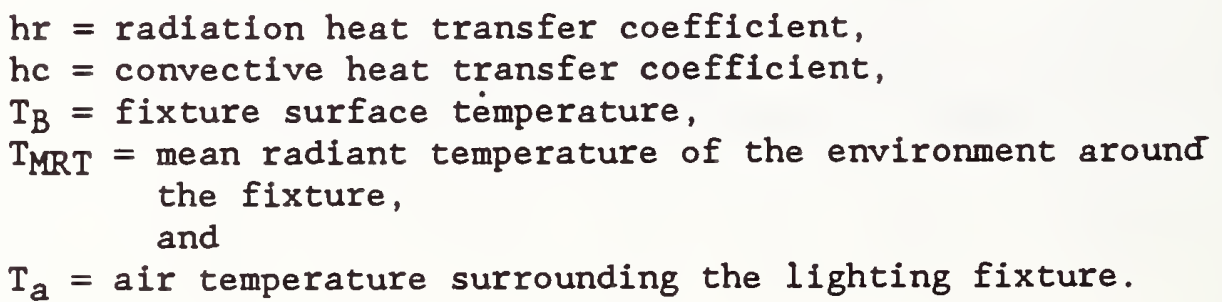


Equations ( 7$),(8)$, and (9) can be used to arrive at:

$$
c_{1}=\frac{R}{P}=\left(\frac{h_{r}}{h_{r}+h_{c}}\right) \frac{1}{1+\frac{h_{c}}{h_{c}+h_{r}} \frac{T_{M R T}-T_{A}}{T_{B}-T_{M R T}}}
$$

Since $\frac{h_{c}}{h_{r}+h_{c}} \quad \frac{T_{M R T}-T_{A}}{T_{B}-T_{M R T}} \leqslant<1$

$$
c_{1} \approx \frac{h_{c}}{h_{r}+h_{c}}\left[1+\frac{h_{c}}{h_{c}+h_{r}} \frac{T_{A}-T_{M R T}}{T_{B}-T_{M R T}}\right]
$$

In many instances, $c_{1}$ is approximated by:

$$
\mathrm{C}_{1}=\frac{\mathrm{hr}}{\mathrm{hr}+\mathrm{hc}}
$$

which is only valid when $T_{a}=T_{M R T}$

In reality, especially during the heating season, $\mathrm{T}_{\mathrm{a}}$ is considerably different from $T_{M R T}$, and is also a strong function of outside temperature $\mathrm{T}_{0}$.

In order to understand the nature and magnitude of energy flows associated with lighting systems, and their interactions with HVAC systems and room design, several issues must be addressed. Of particular importance are the following.

A. Convective heat transfer from the luminaire to the return air.

B. Convective heat transfer from the luminaire to the room air.

C. The distribution of infrared radiant energy from the luminaire.

D. The distribution of short wave radiant energy from the luminaire.

E. The influence of outdoor air temperature.

F. The influence of air duct design.

G. The effect of wall and floor thermal properties.

H. Luminous efficacy vs luminaire heat balance.

This research will address these issues and develop improved and/or extended weighting factors or calculation procedures suitable for annual energy and peak load analysis, as well as for short-time control simulation, to determine the impact on the HVAC system due to operation of lights. 
A test facility will be constructed within the large NBS environmental chamber. The test facility will consist of an outer insulated shell enclosing a simulated office space, with an attached instrumentation room. The simulated office space will consist of a steel structural frame, and concrete floor and ceiling slabs, surrounded by guard air spaces for temperature control. The test room will be configured with or without a plenum space, with an identical configuration below the floor. Identical lighting systems will be installed in both the test room and the lower space.

Conditioning of guard air spaces and test room will be accomplished using separate fan, cooling coil and electric reheat systems. The guard air space temperature conditions will be controlled to maintain zero surface-to-surface temperature difference across the interior walls of the test room, and symmetric conditions between the ceiling and floor.

An extensive microcomputer-based data acquisition system will be used to monitor the various measurement parameters, including electric power, heat and mass flows, and temperatures. Data will be collected and stored every two minutes. Preliminary data reduction will be performed immediately following collection and suspect data will be flagged and warning messages issued.

The basic test run will consist of suddenly energizing the lighting system and waiting for steady state conditions to be achieved or operating the lighting on a daily cycle with steady periodic conditions. Each test will begin with a period to allow the room temperatures to stabilize with the lights off. When steady-state conditions are achieved, the lighting system will be energized and cooling load monitored until it stabilizes. In the lighting daily cycle tests, the lights will be energized for a set period, then turned off for the remaining portion of the day. This cycle will be continued until steady-periodic conditions are achieved (i.e. until cooling load and surface temperature daily profiles do not change).

The current ASHRAE-type weighting factors can be determined from the step change test or the first test cycle. Similar factors can be determined from each successive cycle, although the room temperature conditions will be different for each cycle as the room gradually achieves steady-periodic conditions. The difference in weighting factors determined from each cycle will be a useful indicator of the potential variations in lighting and HVAC performance due to slight variations in room temperature conditions.

The relationship between lighting energy and cooling load for steady periodic conditions will provide the basis for incorporating dynamic lighting system performance within the context of a room heat balance calculation. When the lighting system is 
included in the room heat balance, it is usually necessary to determine lighting energy consumption, which varies with minimum lamp wall temperature, and the fractions of lighting energy which end up being emitted as visible light, emitted as infrared thermal radiation, convected to the plenum, and convected to the room air. The direct measurement of each of these components in an actual installation would be extremely difficult, if not impossible. However, some of the important elements can be measured, and other related parameters, particularly surface temperatures, can be measured and used to verify a numerical model which can in turn be used to determine the various energy fractions.

Thus, a detailed computer model will be generated and adjusted so that the predicted cooling loads and temperature distributions match those observed experimentally. The model will include detailed radiant and convective exchange calculations. 
The test facility was designed to emulate an office space with one exterior wall, surrounded on the other five sides by similar spaces. Details of the architectural, electrical and mechanical design are contained in the following sections.

\subsection{Physical (Architectural)Design}

The test facility will be constructed on a slab $30 \mathrm{ft}$. 6 in. by 21 ft. 4 in., within a large environmental chamber. The facility is divided into two sections, a large insulated shell enclosing the test room, and a smaller attached control room for housing instrumentation, as shown in Figure 1. The overall height of the facility is $20 \mathrm{ft}$. 10-1/2 in., while the control room ceiling height is $13 \mathrm{ft} .2-1 / 2 \mathrm{in}$. The roof of the control room serves as a platform to support some of the HVAC systems (see figure 2).

The test room, which is within the insulated shell, consists of floor and ceiling slabs on steel decking, supported by a steel framework. The space below the floor slab will be operated identically to the test room (i.e. both will have same plenum and lighting configuration) (see figure 3 ).

Initially, the test room will have four interior walls, constructed of drywall and framing. One interior wall will be removed to reveal an exterior wall part-way through the testing schedule. The opposite sides of each of the test room walls will face guard air spaces (see figure 4).

One of the guard air spaces will have the capability of being operated to simulate exterior conditions. Also, large access doors between one guard air space and the chamber can be opened to allow the use of the environmental chamber to provide the exterior temperature conditions, and to allow the use of a solar simulator to incorporate solar effects. Smaller access doors will facilitate entry into the side and top guard air spaces, as shown in figure 5. A door will connect the test room/guard air portion of the facility to the control room, with steps leading from the test room height to the floor of the control room. All of the instrumentation and control equipment will be housed in this space. Chilled water for cooling and electric power will be obtained from the environmental chamber hookups.

The construction specifications call for extreme care in assembling the test room, particularly regarding air tightness, uniformity and insulation concerns. The test room will be as air and vapor-tight as possible, as will the exterior insulated shell. All doors will have gaskets and all joints will be sealed. Measures for verifying air tightness are detailed in the calibration section of this plan. 
Thermal bridges between the test room and the guard air spaces will be minimized, sealed, and insulated. Special attention will be given to the structural elements such as the slab-frame interface.

\subsection{Electrical and Mechanical}

The electrical and mechanical systems in the test facility are essentially similar to typical office building systems, except that there are three air handing units servicing several small spaces. Each of the major air handing systems consists of a fan, a chilled water cooling coil and electric reheat unit. The main system serves the test room, and has a variable speed fan. Temperature control is achieved through electric reheat. Room air temperature will be the control parameter for the test room air handling system. The other air handling systems serve the guard air spaces. Their temperature control is described below. Details of the HVAC systems are shown in figures 6,7 and 8 .

The electrical system is essentially standard except for extensive sub-metering of fan, lighting and reheat power consumptions. Pulse generating watt-hour meters will be used to monitor electrical usages. Six different luminaire types will be available for testing, as listed in table 1. Figure 9 shows the electrical plan.

The temperature of the guard air will be controlled to maintain equal surface temperatures on both sides of each wall. Temperature control will be accomplished using electric reheat, with separate control for each wall. The equal surface temperature condition simulates an adjacent identical room. In such a case, there would be no net heat flow through an interior wall, but heat storage in the wall could occur.

Multi-junction thermopiles will be used to measure the average temperature difference across each wall, producing a voltage proportional to temperature difference. This voltage signal will serve as input to a Proportional Integral Derivative (PID) controller which will vary heat addition to the supply air through electric reheat. The system is shown schematically in figure 10 .

The temperature control for the ceiling and floor slabs is slightly more complicated, however the control strategy remains basically the same as for the walls.

The main difference between the interior walls and the ceiling and floor slabs is that net heat flow can and does occur through the slabs. Net heat flow occurs because the thermal conditions on the bottom of the ceiling are different from the conditions on the top of the ceiling, since the top of the ceiling is really just another floor surface. A floor surface is exposed to the downward fraction of the lighting energy and the room air flow and temperature conditions, while the bottom of the ceiling frequently is contained within a plenum space, and sees the upward fraction of 
the lighting energy. However, vertical symmetry can be obtained by controlling the surface temperature of the top of the ceiling to match the measured floor surface temperature, which is floating with test conditions. The average temperature difference between the top of the ceiling and floor surface will be measured with a multijunction thermopile, the output signal being used to drive a PID controller regulating the level of electric reheat for the top guard air space.

In a similar manner, the temperature of the bottom of the floor (the ceiling of the lower plenum) is controlled to match the bottom of the test room ceiling, which is floating with test conditions. It should be noted that each of the thermopiles will be measuring the average temperature difference between two surface without regard to any variations in temperature across the plane of each surface. This does not present a particularly serious problem for the interior walls, since their surface temperatures will not vary vary rapidly or through a wide range spatially. However, variations in temperature can be expected on the floor and ceiling slabs due to the lighting systems. It is for this reason that a duplicate, identical lighting system will be installed in the lower plenum space. This should provide essentially the same temperature distributions in both slabs.

All of the ductwork will be sealed and insulated. All penetrations due to electrical and mechanical systems will be sealed.

\subsection{Selection of Luminaires for Testing}

A representative selection of luminaire types has been made in an attempt to enable evaluation of the critical design parameters while covering the broad range of potential design options. This initial selection of luminaires is intended to address the primary objective of the overall research program, that of the evaluation of the performance of commercial office lighting systems, thus the evaluation will initially focus on fluorescent luminaires, with various mounting and air-flow configurations.

Table 1 contains a description of the six luminaire types initially selected for testing: 
Table 1

L1 2' $x 4^{\prime}$ Fluorescent Fixture; 4 lamp, recessed; combination troffer, static and air handling; ballasts, high power factor, rapid start; diffuser, acrylic, .125 inches thick; with lamps; with side slot closures, and heat removal dampers; with written directions for alternate operations; Lithonia 2 GCD440-ACS, 120 volt.

L2 1' $\times 4^{\prime} 2$ lamp Fluorescent Fixture; similar to L1

L3 2' $\times 4^{\prime}$ Fluorescent Fixture; similar to L1 except with $3^{n}$ parabolic louver, air pattern control blades, and heat removal dampers; Lithonia 2PM3GCD440

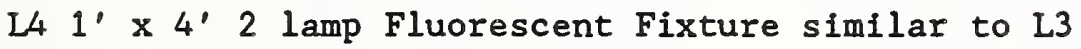

L5 2' $\times 4^{\prime}$ Fluorescent Fixture; wrap around diffuser, acrylic; with 4 lamps; ballasts same as L1; with surface and stem mount hardware; Lithonia LB 440 or equal

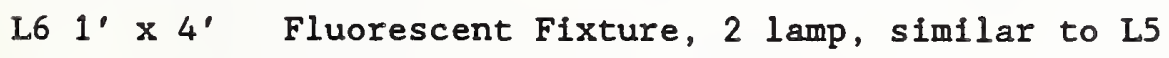


The instrumentation system serves three basic purposes, namely data collection, data analysis and experimental control. A microcomputer-based data acquisition system will be utilized to execute the testing, collect and store the data and to perform initial data analysis. It is possible that some or all of the data will be transferred to a main frame computer for subsequent processing, if that seems useful. Most of the data analysis will be performed on a microcomputer dedicated to that use.

The testing revolves around two primary variables, cooling (or heating) load and lighting power. The traditional ASHRAE-type weighting factor approach is based on determining the relationship between cooling load and lighting load following a step change in lighting load, with all other environmental conditions remaining constant. The ASHRAE method is also based on the assumption that all of the lighting energy eventually becomes cooling load, thus not accounting for heat gain or loss through exterior wall or window. The ASHRAE method primarily accounts for heat storage in the floor and ceiling slabs.

The current measurements will allow determination of lighting and cooling relationship for a variety of HVAC and exterior conditions, but the primary variables will still be cooling load and lighting energy. Many other measurements will be made to support the primary measurements, to characterize the test room conditions and for model validation. Where possible, redundant measurement systems will be implemented.

The measurement sensors will be connected to a data acquisition system under the control of a network consisting of three microcomputers. The data acquisition system will perform signal conditioning and analog-to-digital conversion form, while the microcomputers will process, store and analyze the measured data. Initial data processing will involve built in checks for data accuracy and experimental system performance. Additional real-time processing will include computation of ASHRAE-type weighting factors and other statistical information related to the testing results.

\subsection{Measurement Parameters}

\subsubsection{Lighting Power}

This is one of the primary measurement parameters and, fortunately, one of the easier measurements to make accurately. lighting power consumption will be measured using pulse-generating watt-hour meters, sized to produce about one count per 10 seconds. Both lighting energy usage, the total number of counts in an interval, and instantaneous lighting power, the pulse rate, can be determined to within one percent. 


\subsubsection{Cooling (or Heating) Load}

This is the second primary measurement parameter, one which presents more difficulties than the measurement of lighting power. Within the context of this testing program, room cooling load represents the energy which must be extracted from the room, including plenum space, in order to maintain the desired temperature condition. Of course, if heat must be added to the room the load is actually a heating load; however, for simplicity the term cooling load will be used to describe the room thermal load.

The determination of cooling load requires the measurement of more than one variable, and can be accomplished in several ways, each with its own advantages and disadvantages. One method would be to measure the supply and return air flow rates, and the temperature change of the air between the supply and return. Then, the change in enthalpy of the air could be calculated using the appropriate thermal property data, according to:

$$
\mathrm{Qc}_{c}=\mathrm{h}=\mathrm{m} \mathrm{C}_{\mathrm{p}} \quad \Delta \mathrm{T}
$$

where:

$$
\begin{aligned}
Q c & =\text { room cooling load } \\
\Delta \mathrm{h} & =\text { enthapy change } \\
\mathrm{m} & =\text { mass flow rate of air } \\
\mathrm{C}_{\mathrm{P}} & =\text { constant pressure specific heat } \\
\Delta \mathrm{T} & =\text { temperature change of air }
\end{aligned}
$$

This method will be the primary means of determining room cooling load. Since the room is airtight, except for supply and return air, then the air flow rate need be measured only at the supply. The temperature change between the supply and return air will be measured using multijunction thermopiles, located at the room boundary. An additional thermopile will be used to measure air temperature change within the plenum, when a plenum is used. The ratio of these two measurements will indicate the percentage of heat pickup above the plenum.

Multijunction thermopiles of Type $T$ (copper-constantan) wire can be designed to be very sensitive when many junctions are used. In addition, the multiple junctions allow measurements over a large area to determine the true average temperature difference.

Air flow rate will be measured using a commercially available anemometer, consisting of a flow straightener and thermister 
array. The stated uncertainty of the sensor is less than three percent. The sensor output is a voltage signal which is proportional to mass flow. The mass flow rate can be determined from:

$\mathrm{H}=\mathrm{Av}$

where:

$A=$ flow area

$v=$ mass flow velocity

The instantaneous cooling load due to lighting, $\mathrm{Q}_{\mathrm{L}}$, is determined by subtracting any other heat sources from the room load $Q_{C}$.

thus:

$$
Q_{L}=Q_{C}-Q_{E}-Q_{I}
$$

where:

$$
\begin{aligned}
& Q_{E}=\text { heat gain from exterior } \\
& Q_{I}=\text { heat gain from interior equipment }
\end{aligned}
$$

As a supporting measurement the product $m C_{p}$ for the supply air will be determined by measuring the temperature rise $\Delta \mathrm{T}$ of the air across the electric reheat unit, according to:

$$
\mathrm{mC}_{\mathrm{p}}=\frac{\mathrm{E}}{\Delta \mathrm{T}}
$$

where:

$$
E \text { = heat addition by electric reheat }
$$

The product $\mathrm{mC}_{\mathrm{p}}$ can be determined from measurement during fairly stable conditions. Thus, room cooling load can be determined by two direct measurement methods. A third method will also be used, one which provides additional information about the system performance. This third method is based on cooling coil load at the water-to air heat exchanger in the test room air circulation loop. The heat extracted from the return air by the cooling coil consists of heat gain from lighting and electric equipment, heat gain through exterior surfaces, heat gain from lighting and electric equipment, heat gain through exterior surfaces, heat gain from the circulation fan and heat gain from the electric reheat. 
Thus, under steady state conditions,

$$
Q_{C c}=Q_{L}+Q_{E}+Q_{I}+Q_{F}+Q_{R}+Q_{D}
$$

where:

$$
\begin{aligned}
& Q_{C C}=\text { cooling coil load } \\
& Q_{F}=\text { heat gain from fan } \\
& Q_{R}=\text { heat gain from reheat } \\
& Q_{D}=\text { duct heat gain }
\end{aligned}
$$

The cooling coil load can be determined from measurement of water flow rate and temperature rise across the heat exchanger, accounting for thermal storage effects. The other electric heat sources, $Q_{I}, Q_{F}$ and $Q_{R}$, will be measured with pulse-generating watt hour meters. Then $\mathrm{Q}_{\mathrm{L}}$ can be determined from

$$
Q_{L}=Q_{C C}-Q_{E}-Q_{I}-Q_{F}-Q_{R}-Q_{D}
$$

provided that $Q_{E}$ is known. Initially, $Q_{E}$ will be zero. During subsequent tests under summer and winter conditions, $Q_{E}$ will be measured using heat flow meters. Duct heat gain will be small, but a correction for the effect can be made from a combination of temperature and heat flow measurements.

\subsubsection{Surface Temperatures}

Extensive measurements will be made of surface temperatures throughout the test facility. The measurements will serve three purposes. First, they will allow the characterization of the test conditions, supporting the basic measurements. Second, they will be used to generate and validate the computer simulation models. Third, they will allow real-time diagnosing of control system performance.

Temperature measurements will be made using type $T$ thermocouples, whenever precision temperature difference measurements are needed, multijunction thermopiles will be used.

Since the test room is symmetric about an axis in the center of the room normal to the window wall, temperatures and heat flows should be nearly equal in the east and west halves of the test room. Thus, detailed measurements only need to be made over one half of the test room. Figure 11 shows the locations of the wall, floor and ceiling thermocouples. Only two luminaires need to be measured. Each will be instrumented with 16 thermocouples, distributed on the fluorescent tube and fixture.

\section{1 .4 Air Temperatures}

Thermocouples will be used to measure room air temperature distribution, according to figure 12. Temperature will be measured at four heights at each location. Radiation shields will be used to minimize radiative coupling. Additional air tempera- 
ture measurements will be made throughout the guard air spaces and the air handling systems.

\section{1 .5 Heat Flows}

Heat flow at the interior surface of the test room envelope will be measured using heat flux transducers. These transducers will be located as shown in figure 13. Each transducer develops a low-level dc voltage proportional to heat flow at the measurement location. Total heat flow through each component of the room envelope will be determined by suitable area-weighted averaging of the individual measured heat flows.

\subsubsection{Light Levels}

The illuminance incident upon each room surface will be measured with photovoltaic silicon cells. Single cells will be permanently located at the center of each surface. An additional movable array of cells will be used to evaluate illuminance distributions.

\subsubsection{Long-Wave Infrared Radiation}

The long-wave radiant energy incident upon each room surface will be measured using pyrgeometers. Thermographic imaging equipment and spot radiometers will be used to evaluate radiant interchange conditions and temperature distributions for different luminaire designs.

\subsection{Data Collection and Analysis}

Measurements will be recorded at two minute intervals for the entire set of measurement parameters. The recorded value will consist of the average of ten equally spaced readings during the two minute interval, for a twelve second sampling interval. Each twelve second reading will be computed as the average of a number sequential measurements. Error detection and correction programs will be used to improve measurement accuracy.

A few important parameters will be stored at twelve second intervals for modeling, control and analysis purposes. These parameters include lighting power, cooling load, minimum lamp wall temperature and room air temperature.

Each measurement input will be checked for accuracy and to verify proper operation of the sensor and data acquisition system. This checking will involve intercomparisons of related measurement parameters, and checks against theoretical constraints. Any anomalous data will be flagged and an error message will be issued to the control monitor and automatically recorded in the testing log.

Each test will consist of up to a week of measurements. The data recorded for each test will be stored individually on magnetic media for subsequent processing. Real time data analysis will 
include the calculation of ASHRAE-type weighting factors during each daily cycle, heat balance analysis of lighting/room system and other heat transfer calculations. 


\section{TESTING PROCEDURE}

The general testing procedure consists of initially establishing a set of wall and lighting conditions. That configuration would then be tested by operating the lighting on a step change or cyclic schedule until room thermal loads and temperature conditions achieve steady periodic state. At that point, one or more of the design parameters will be changed and the new configuration will be tested as before. While testing continues, previously collected data will be analyzed.

The list of variable parameters includes the following:

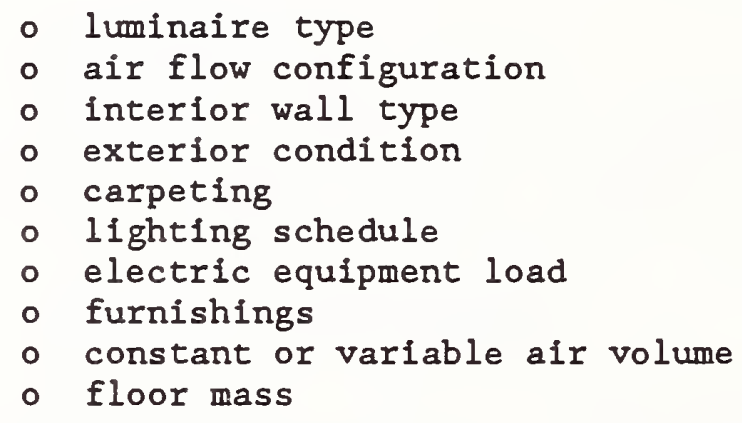

Some of these parameters are easily altered, such as lighting schedule or electric equipment load. Others, such as interior wall type, are difficult to change, so changes will be made only infrequently. 


\section{CALIBRATION AND TESTING}

Several calibration procedures will be utilized, both during shakedown testing and periodically as required.

\subsection{Initial Calibration and Testing}

The initial testing efforts will be aimed towards verifying air tightness of the test room, ducts and insulated shell, and locating any thermal bridges or construction defects. Once any problems are identified, corrective action will taken. Air tightness will be measured using sulfur-hexafluoride $\left(\mathrm{SF}_{6}\right)$ tracer gas measurements. The leakage rates for each air zone and air handling system will be measured. Thermographic imaging equipment will be used to search for thermal anomalies. Air flow rates and distributions will be measured in each of the zones.

The control systems will be set to maintain steady-state conditions, so that an overall heat-balance analysis can be performed on the test room, both with lights on and off.

The measurement transducers will be calibrated before installation, and their performance will be rechecked periodically. The primary calibration efforts will involve the air flow sensor, electric power meters, heat flux transducers and water flow meter.

\subsection{Periodic Calibration and Testing}

Real-time analysis of the measurement data will help the identification of sensor malfunctions. The flow sensors and electric meters will be periodically recalibrated. Additional air tightness measurements will also be performed periodically. 


\section{TESTING SCHEDULE}

Testing will begin following the completion of the test facility construction. An initial period of four months will be used for calibration and shakedown testing. This will also provide a chance for some sensitivity testing and analysis. Due to the large number of potential test configurations, only a small percentage of configurations can be tested, so it is important that the test configurations be chosen so that the significant effects of each important variable can be evaluated. Thus, during the sensitivity and shakedown testing, each easily varied parameter will be varied at least once from baseline conditions.

The following table contains a listing of each variable parameter, including an identification code for reference in the testing schedule variation of parameters.

Table 2 Listing of Variable Parameters

\section{Parameter}

Code

1. Luminaire type

- $2 \times 4,4$ lamp, recessed L1

- $1 \times 4,2$ lamp, recessed L2

- $2 \times 4,4$ lamp, parabolic L3

- $1 \times 4,2$ lamp, parabolic L4

- $2 \times 4,4$ lamp, surface L5

- $1 \times 4,2$ lamp, surface L6

2. Supply Air

- ceiling s1

- luminaire s2

3. Return Air

- ceiling plenum, no duct R1

- ceiling plenum, with duct R2

- luminaire, no duct R3

- luminaire, with duct $\quad$ R4

- high sidewall, no plenum R5

4. Walls

- four foil covered foam W1

- four interior drywall W2

- three interior drywall, one exterior curtain W3

- three interior block, one exterior block W4

5. Exterior Condition

- none

- summer

E1

- winter 
6. HVAC

- constant air volume H1

- variable air volume H2

- fan coil unit H3

7. Floor

$\begin{array}{ll}\circ \quad 2-1 / 2 " \text { concrete, bare } & F 1 \\ \circ \quad 2-1 / 2 \text { " concrete, carpet } & \text { F2 } \\ \circ \quad 4 " \text { concrete, bare } & \text { F3 } \\ \text { - 4" concrete, carpet } & \text { F4 }\end{array}$

Due the necessary construction changes, option W4 (block walls) will not be undertaken until all other testing is completed, and options F3 and F4 will also be deferred.

Also, the fan coil unit tests (H3) will be run following the other numerous HVAC design combinations.

Four months time has been allotted for calibration and shakedown testing. This should allow for about 12 sensitivity tests. This testing will allow for preliminary analysis of the sensitivity of the measurements to the variable parameters, while at the same time allowing tuning and adjustment of the various control and data collection systems. Table 3 presents the schedule for shakedown testing.

Table 3. Schedule for Sensitivity Testing.

Test Number

1
2
3
4
5
6
7
8
9
10
11
12

\section{Configuration Code}

L1, S1, R1, W1, E1, H1, F1
L2, S1, R2, W1, E1, H1, F1
L1, S1, R3, W1, E1, H1, F1
L1, S1, R4, W1, E1, H1, F1
L1, S1, R1, W1, E1, H2, F1
L1, S1, R2, W1, E1, H2, F1
L1, S1, R3, W1, E1, H2, F1
L1, S1, R4, W1, E1, H2, F1
L3, S1, R1, W1, E1, H1, F1
L3, S1, R2, W1, E1, H1, F1
L1, S1, R1, W1, E1, H1, F2
L1, S2, R1, W1, E1, H1, F1

The schedule for the primary testing will depend in part on the results of the sensitivity testing and related computer simulations and indeed on the results obtained from the initial primary testing. An optimistic testing schedule would call for about 50 tests, each lasting roughly a week. Given this target, table 4 lists a tentative schedule for the primary testing. 
Table 4. Schedule for Primary Testing

Test Number

1

2

3

4

5

6

7

8

9

10

11

12

13

14

15

16

17

18

19

20

21

22

23

24

25

26

27

28

29

30

31

32

33

34

35

36

37

38

39

40

41

42

43

44

45

46

47

48

49

50
Configuration Code

L2, S1, R1, W1, E1, H1, F1

L5, S1, R5, W2, E1, H1, F1

L5, S1, R5, W2, E1, H2, F1

L5, S1, R5, W2, E1, H1, F2

L5, S1, R5, W2, E1, H2, F2

L2, S1, R1, W2, E1, H1, F1

L2, S1, R3, W2, E1, H2, F1

L2, S1, R1, W2, E1, H2, F1

L2, S1, R1, W2, E1, H1, F2

L2, S1, R1, W2, E1, H2, F2

L2, S1, R1, W3, E2, H1, F1

L2, S1, R2, W3, E2, H1, F1

L2, S1, R3, W3, E2, H1, F1

L2, S1, R4, W3, E2, H1, F1

L2, S1, R1, W3, E2, H2, F1

L2, S1, R2, W3, E2, H2, F1

L2, S1, R3, W3, E2, H2, F1

L2, S1, R4, W3, E2, H2, F1

L4, S1, R1, W3, E2, H1, F1

L4, S1, R2, W3, E2, H1, F1

L4, S1, R3, W3, E2, H1, F1

L4, S1, R4, W3, E2, H1, F1

L4, S1, R1, W3, E2, H2, F1

L4, S1, R2, W3, E2, H2, F1

L4, S1, R3, W3, E2, H2, F1

L4, S1, R4, W3, E1, H2, F1

L2, S1, R1, W3, E2, H1, F2

L2, S1, R3, W3, E2, H1, F2

L2, S1, R1, W3, E2, H2, F2

L2, S1, R3, W3, E2, H2, F2

L1, S1, R1, W3, E2, H1, F1

L1, S1, R3, W3, E2, H1, F1

L3, S1, R1, W3, E2, H1, F1

L3, S1, R3, W3, E2, H1, F1

L4, S1, R1, W3, E2, H1, F2

L4, S1, R3, W3, E2, H1, F2

L4, S1, R1, W3, E2, H2, F2

L4, S1, R3, W3, E2, H2, F2

L2, S1, R1, W3, E3, H1, F1

L2, S1, R2, W3, E3, H1, F1

L2, S1, R3, W3, E3, H1, F1

L2, S1, R4, W3, E3, H1, F1

L4, S1, R1, W3, E3, H1, F1

L4, S1, R2, W3, F3, H1, F1

L4, S1, R3, W3, E3, H1, F1

L4, S1, R4, W3, E3, H1, F1

L2, S1, R1, W3, E3, H1, F2

L2, S1, R1, W3, E3, H2, F2

L2, S1, R4, W3, E3, H1, F2

L2, S1, R4, W3, E3, H2, F2 
As is seen from the preceding schedule, the changeover to block walls is not included in the first 50 configurations. This is because such a changeover involves disassembling the gypsum walls and building the block walls in place, thus preventing anymore tests with drywall. This construction work will prevent testing during the changeover, and it is felt that the wall change should be delayed as long as possible. If necessary for contractural reasons, the wall changeover could be moved up, at the expense of testing time. 
9. REFERENCES

1. Sowell, E., "A General Model for the Transport of Lighting Thermal Power," California State University.

2. Ball, H., Green, D., "The Impact of Lighting Fixtures on Heating and Cooling Loads - Mathematical Model," ASHRAE Transactions, Vol. 89, 1983.

3. Kimura, K., Stephenson, D., "Theoretical study of Cooling Load Caused by Lights," ASHRAE Transactions, Vol. 74, Part II, 1968 .

4. Mitalas, G., "A Calorimeter to Determine Cooling Load Caused by Lights," ASHRAE Transactions, Vol. 77, Part II, 1971.

5. Mitalas, G., "Transfer Function Method of Calculating Cooling Loads, Heat Extraction and Space Temperature," ASHRAE Journal, Vol. 14, No. 12, Dec. 1972.

6. Mitalas, G., "Cooling Load Caused by Lights," Transactions of Canadian Society for Mechanical Engineering, Vol.2, No. 3, 1973.

7. Mitalas, G., "Calculating Cooling Load Caused by Lights," ASHRAE Journal, Vol. 15, No. 6, June 1973.

8. Ball, H., "The Impact of Lighting Fixtures on Heating and Cooling Loads - Application to Design," ASHRAE Transactions, Vol. 89, 1983.

9. Siminovitch, M., Rubinstein, F., Clark, T., Verderber, R., "A Luminaire/Plenum HVAC Simulator," Proceedings IEES-IAS, Conference, Toronto, Oct. 1985. 


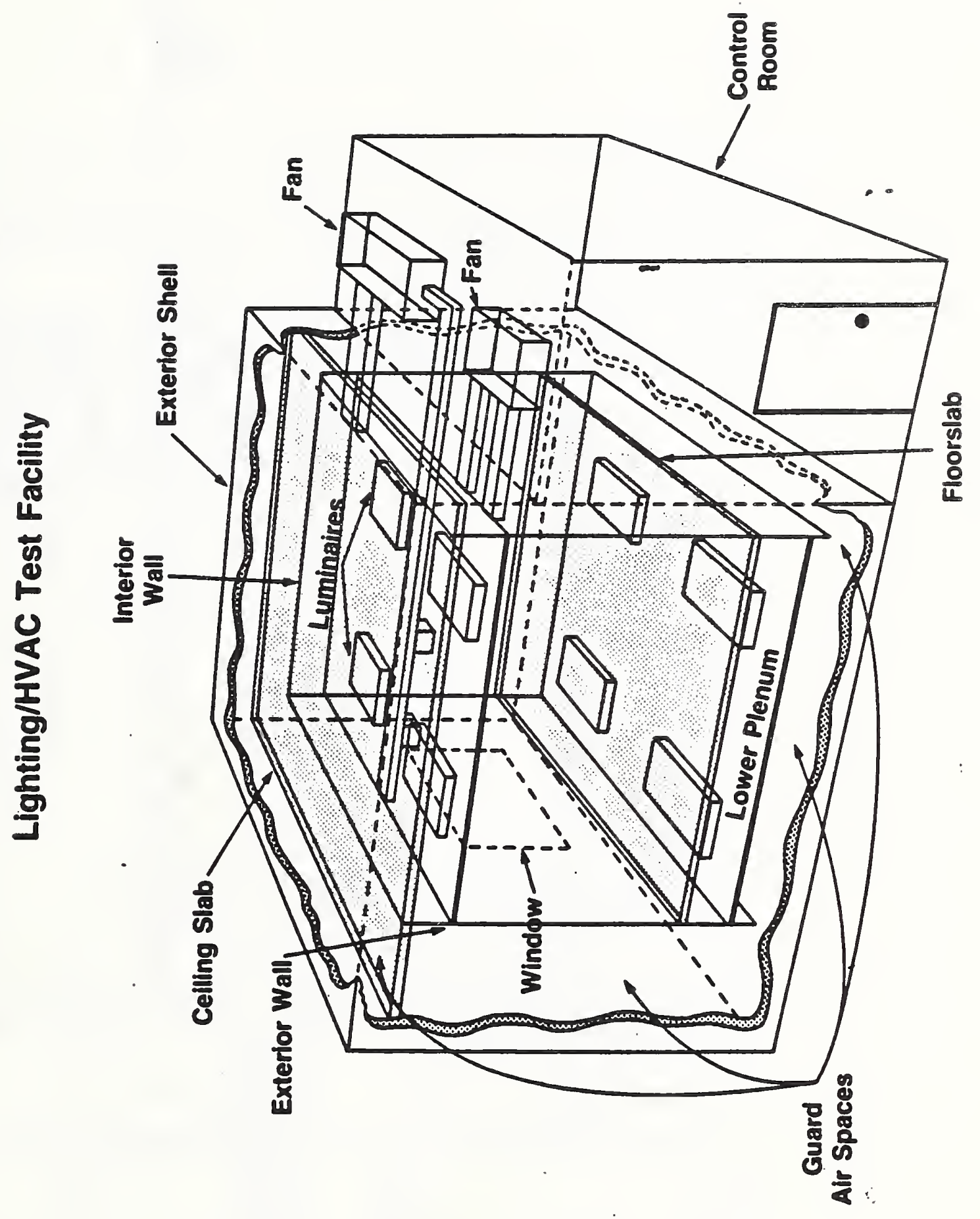

Figure 1. Schematic of Test Facility 


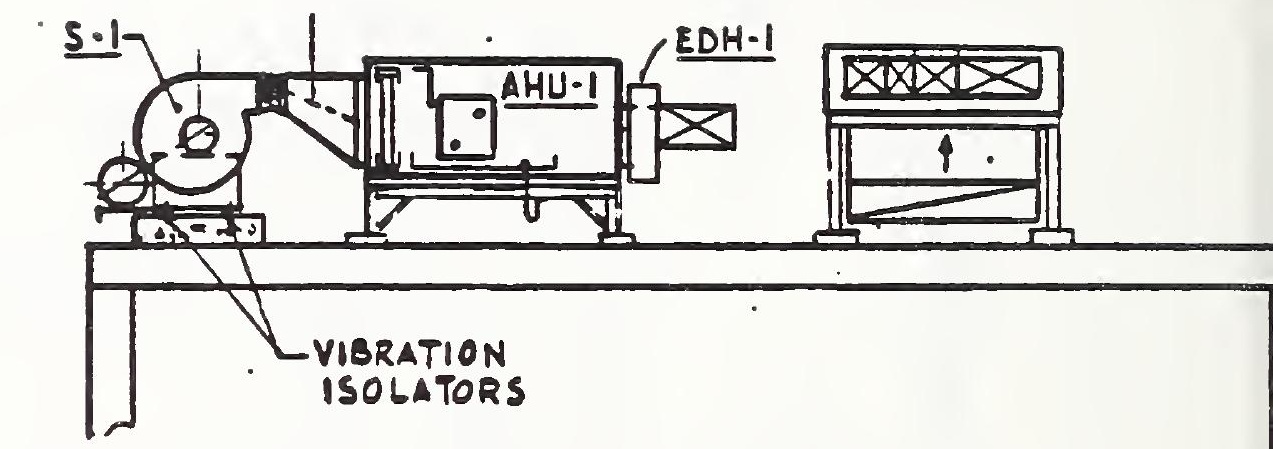

Figure 2. Control room roof supports HVAC equipment 
Figure 3. Test room slabs and steel support frame

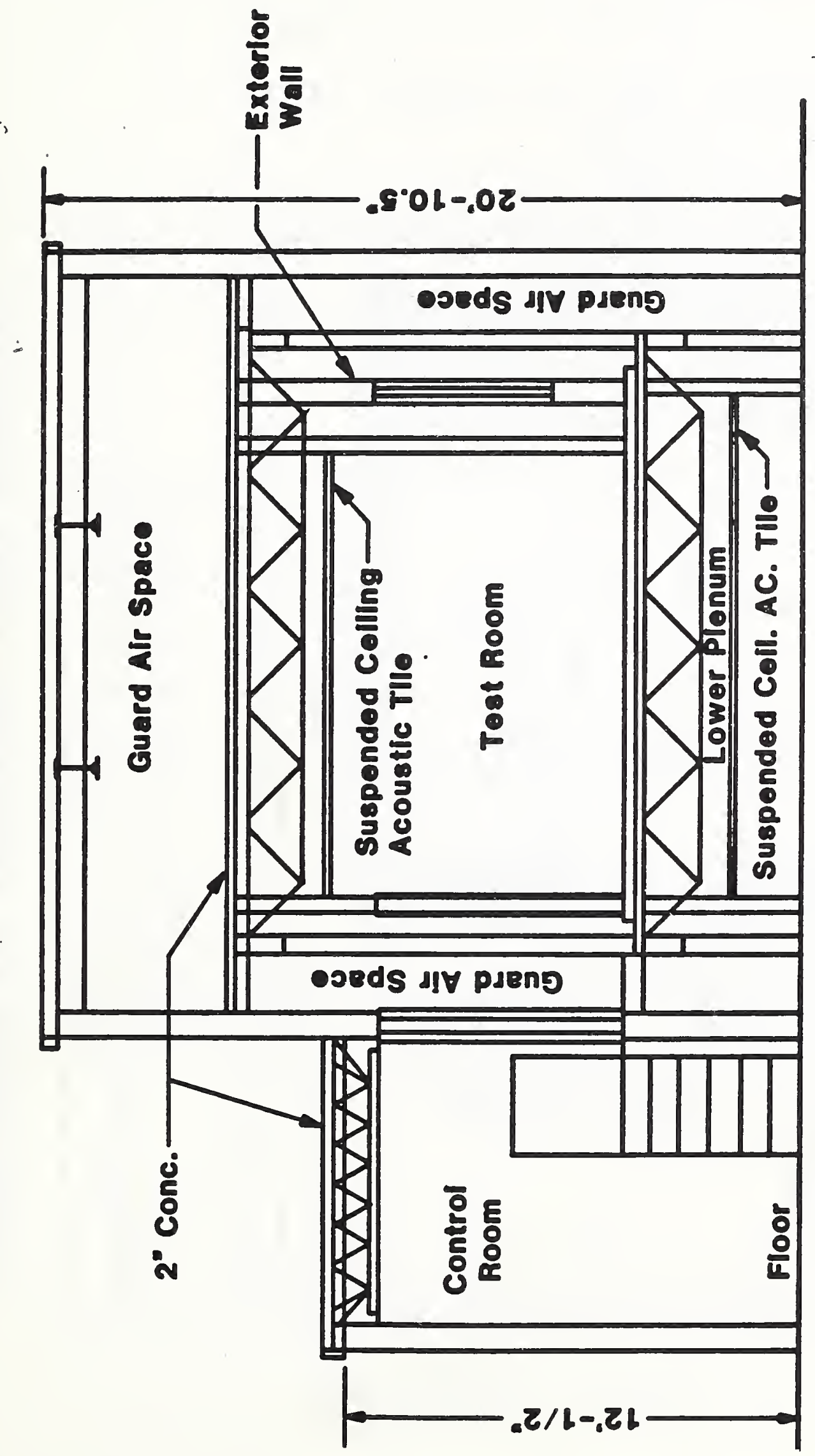




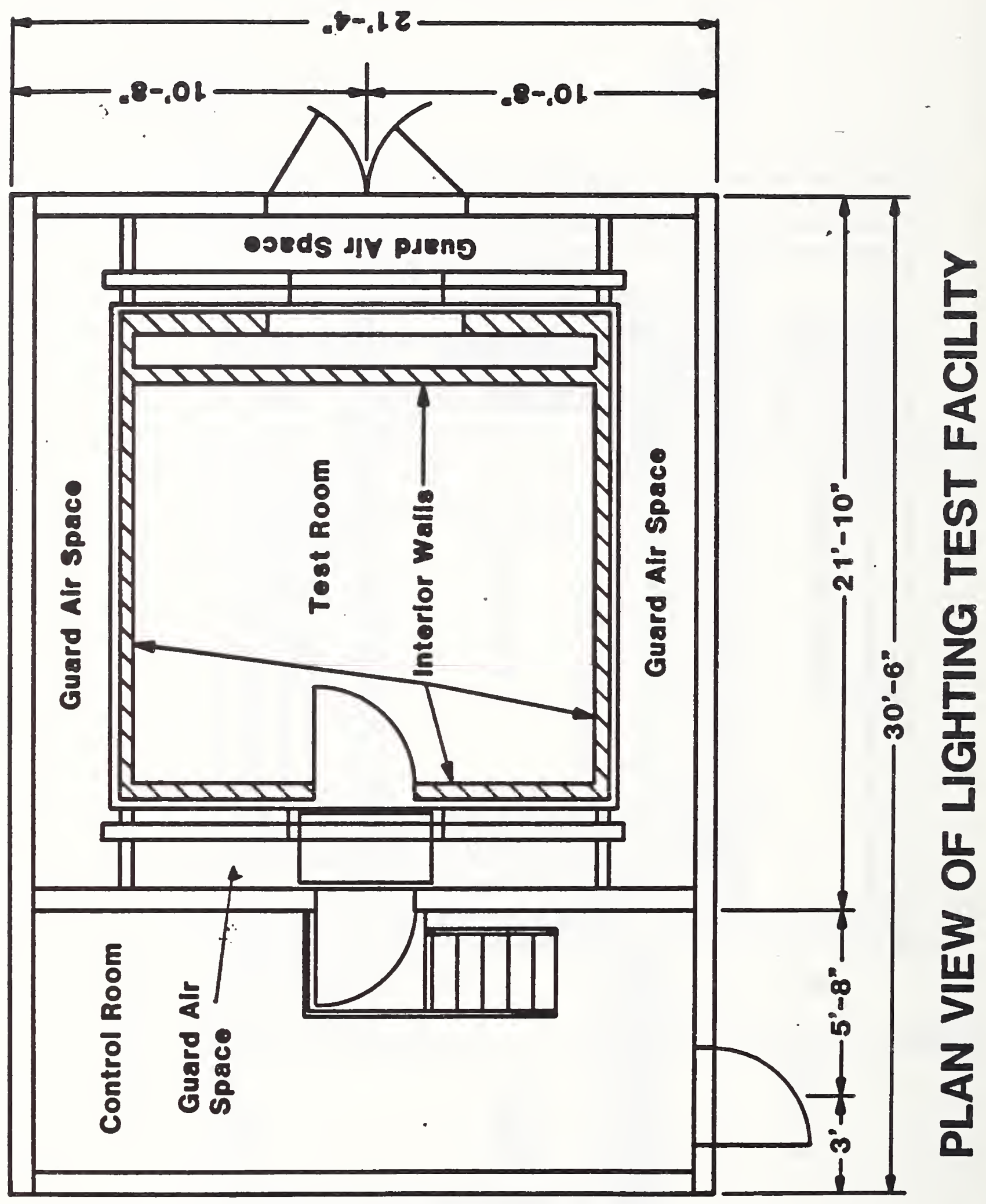

Figure 4. Guard air spaces 


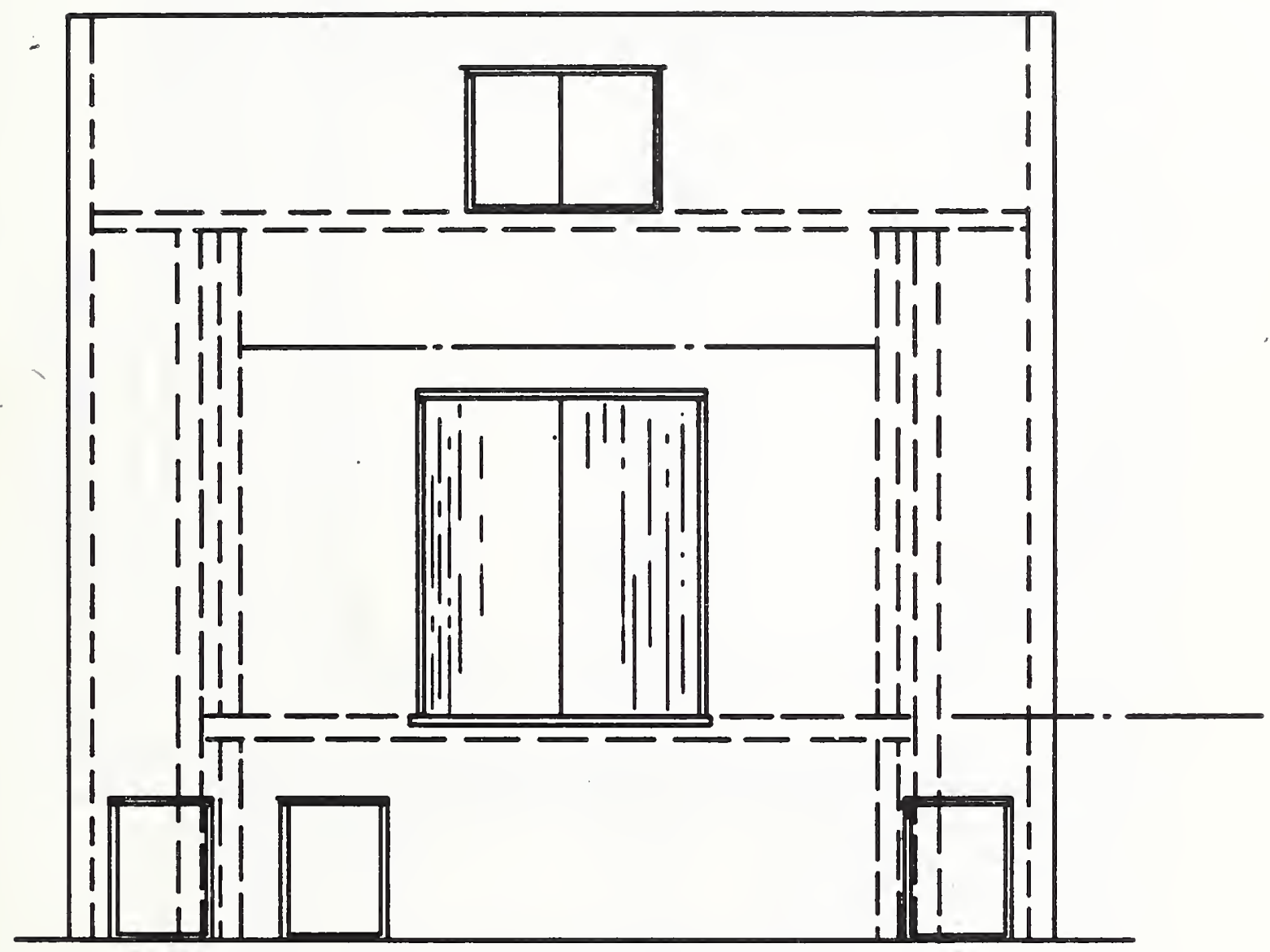

Figure 5. Access doors 


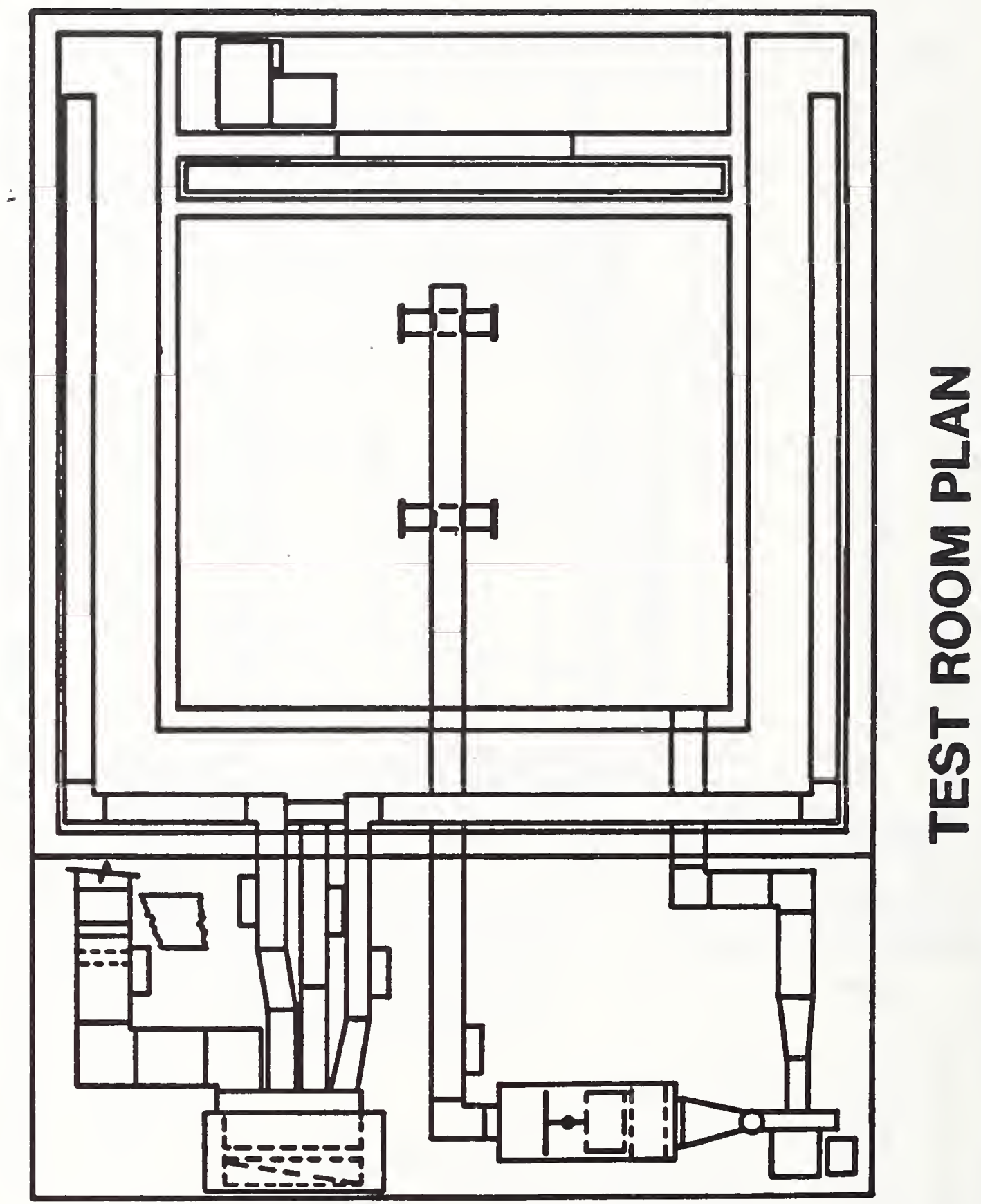

Figure 6. Air Handling Unit \#1, test room and \#2, Guard Air. 


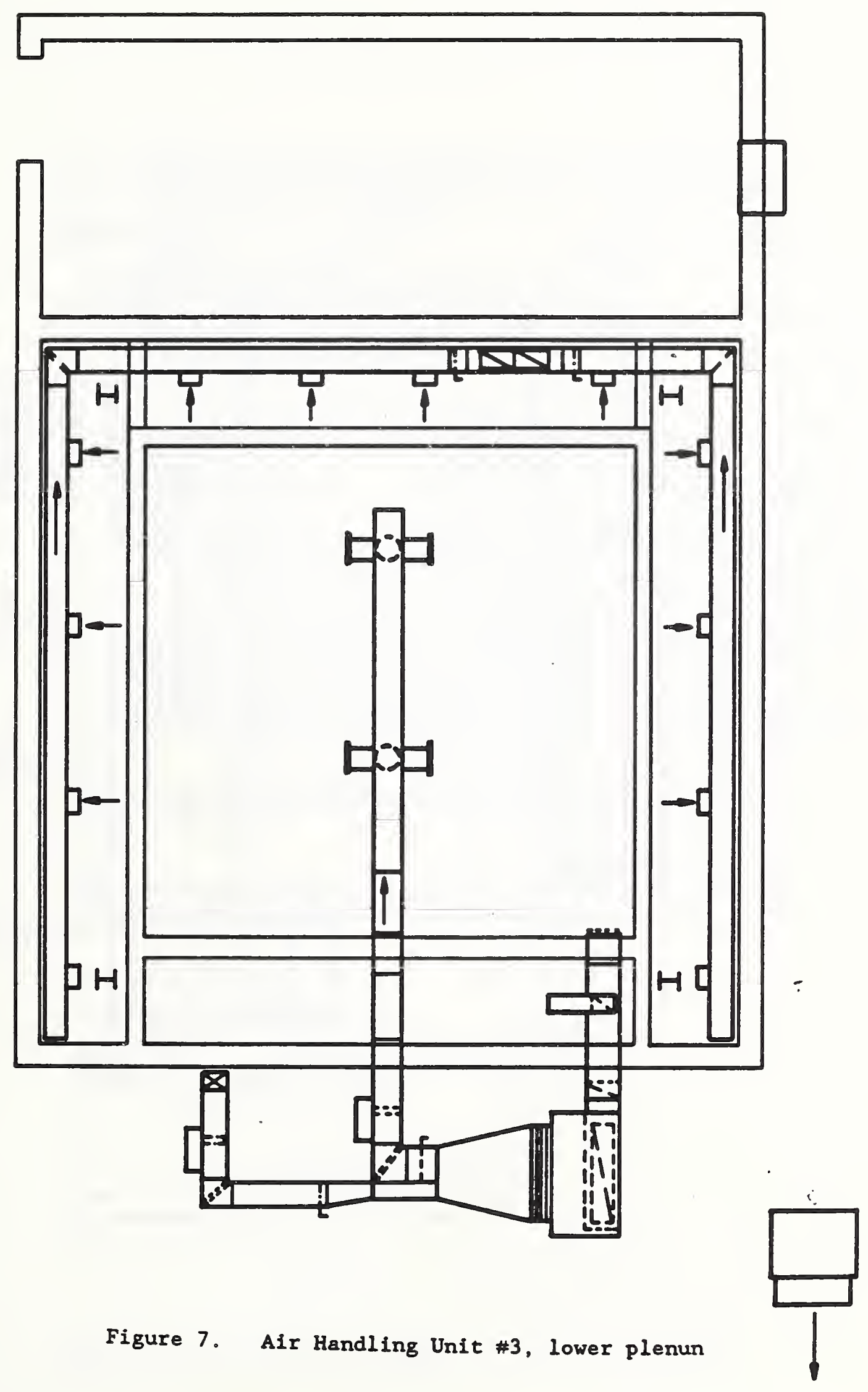




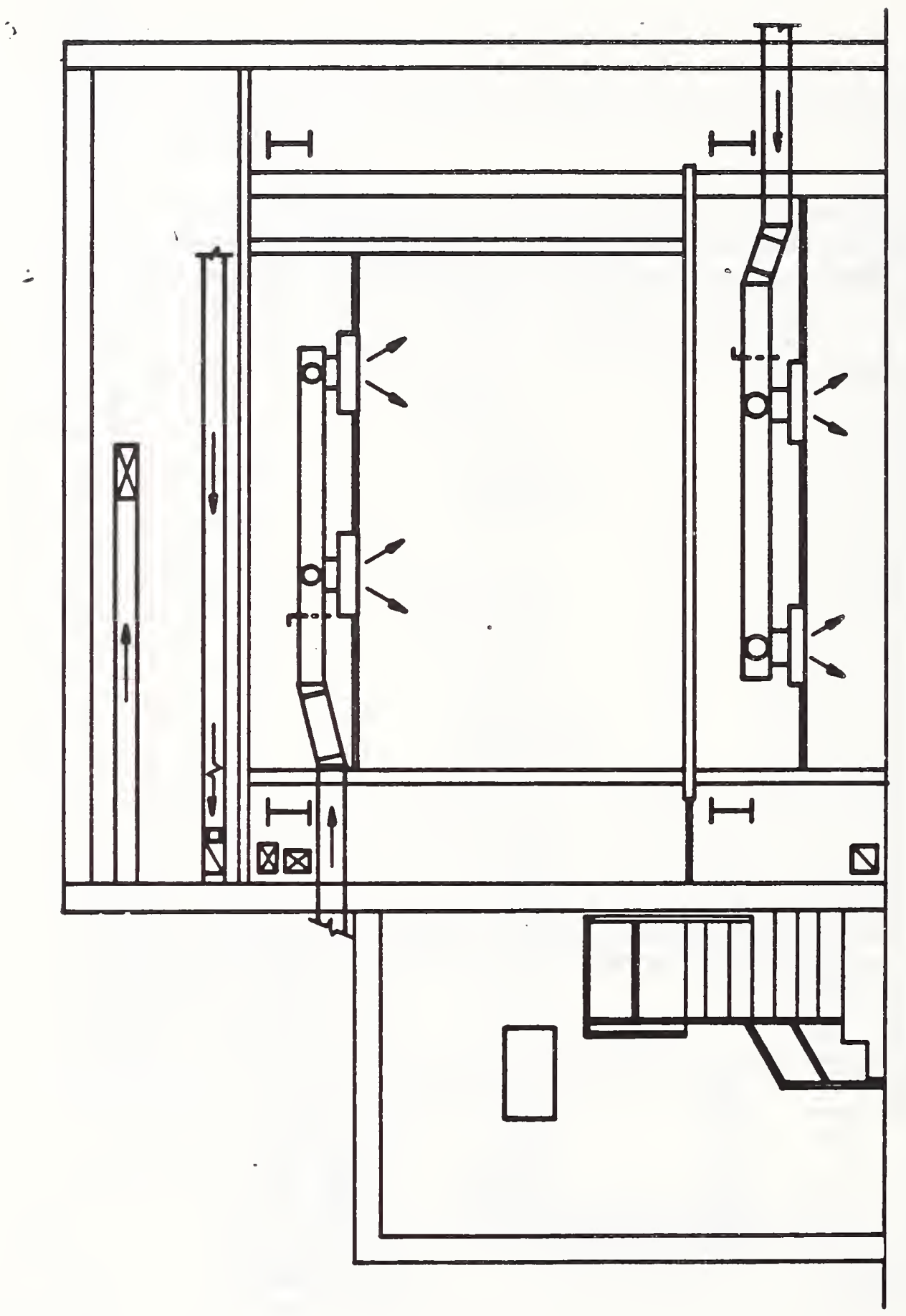

Figure 8. Supply and return ductwork for test room 


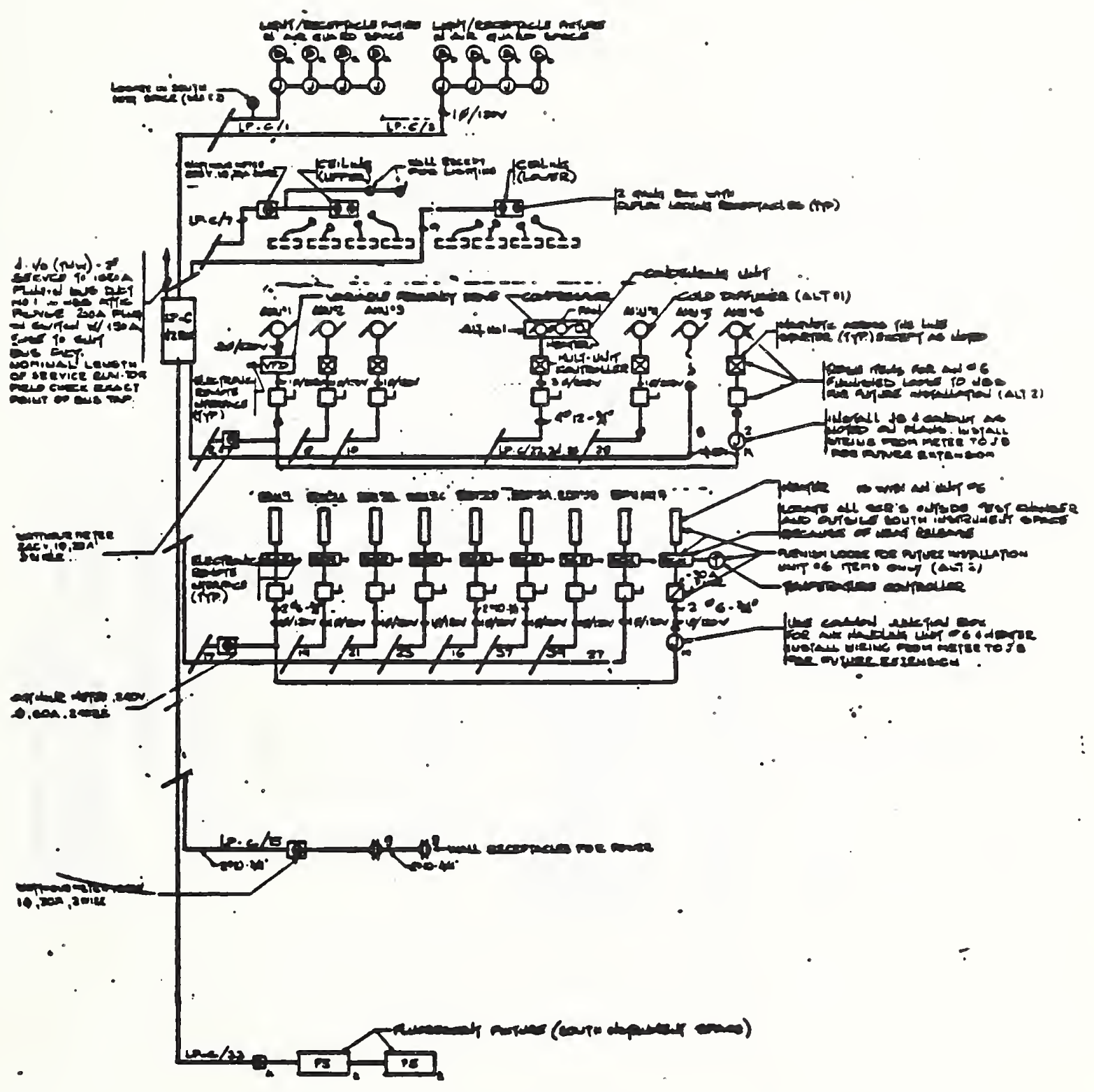

POWER RISER DIAGRAM

(NIS)

Figure 9. Electrical plan 


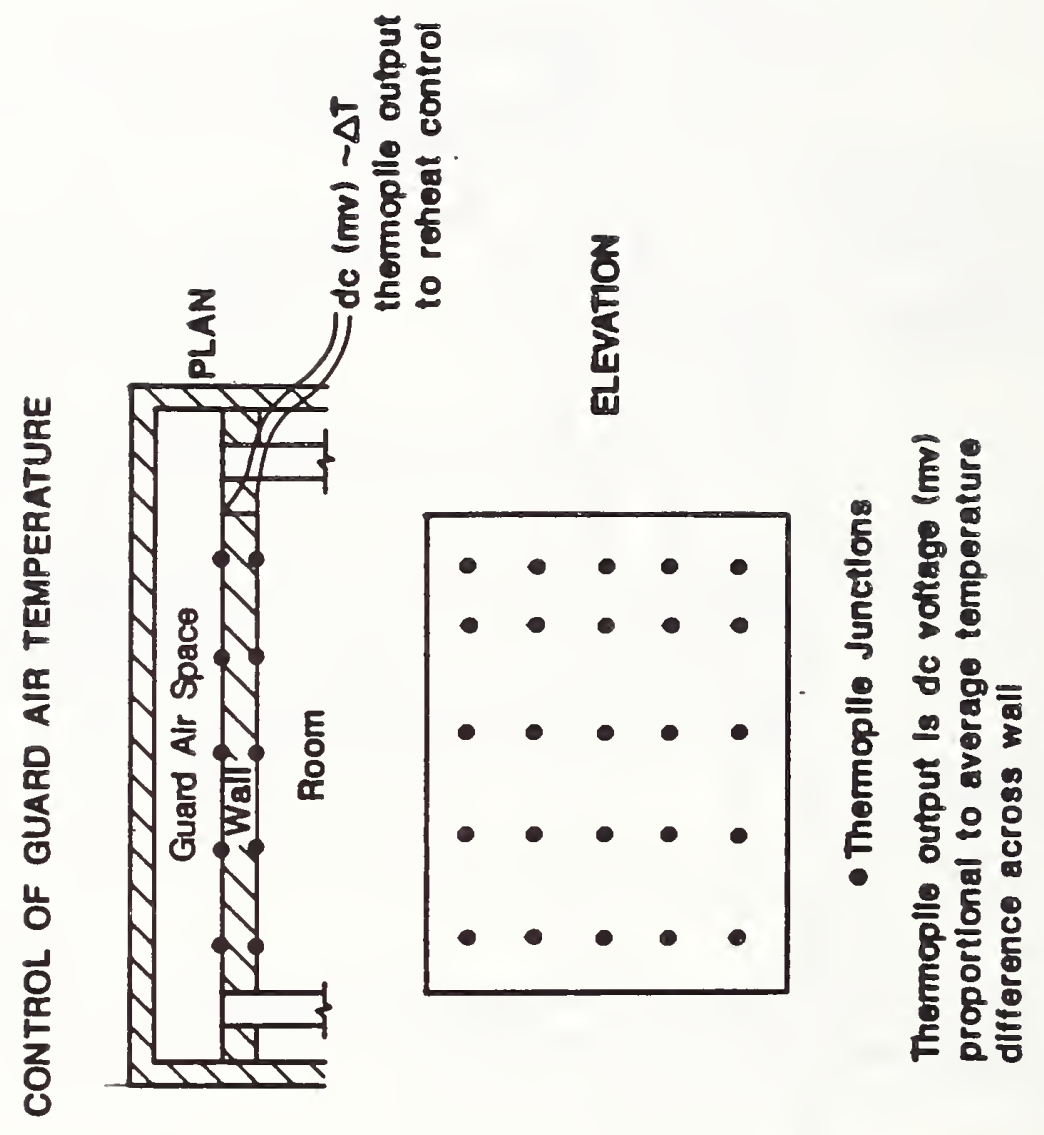

Figure 10. Schematic of guard air temperature control 


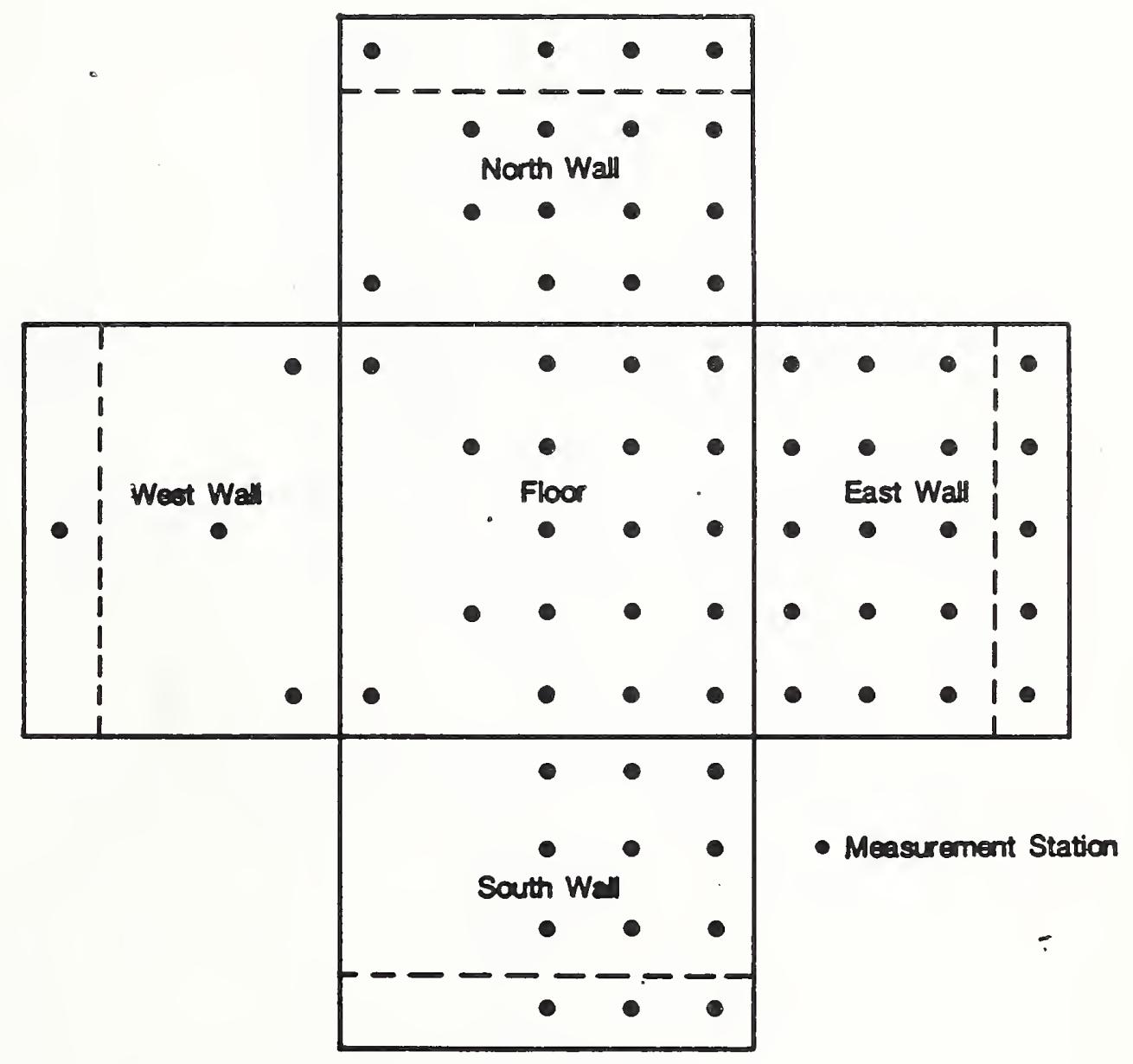

Figure 11. Locations of surface temperature measurements 


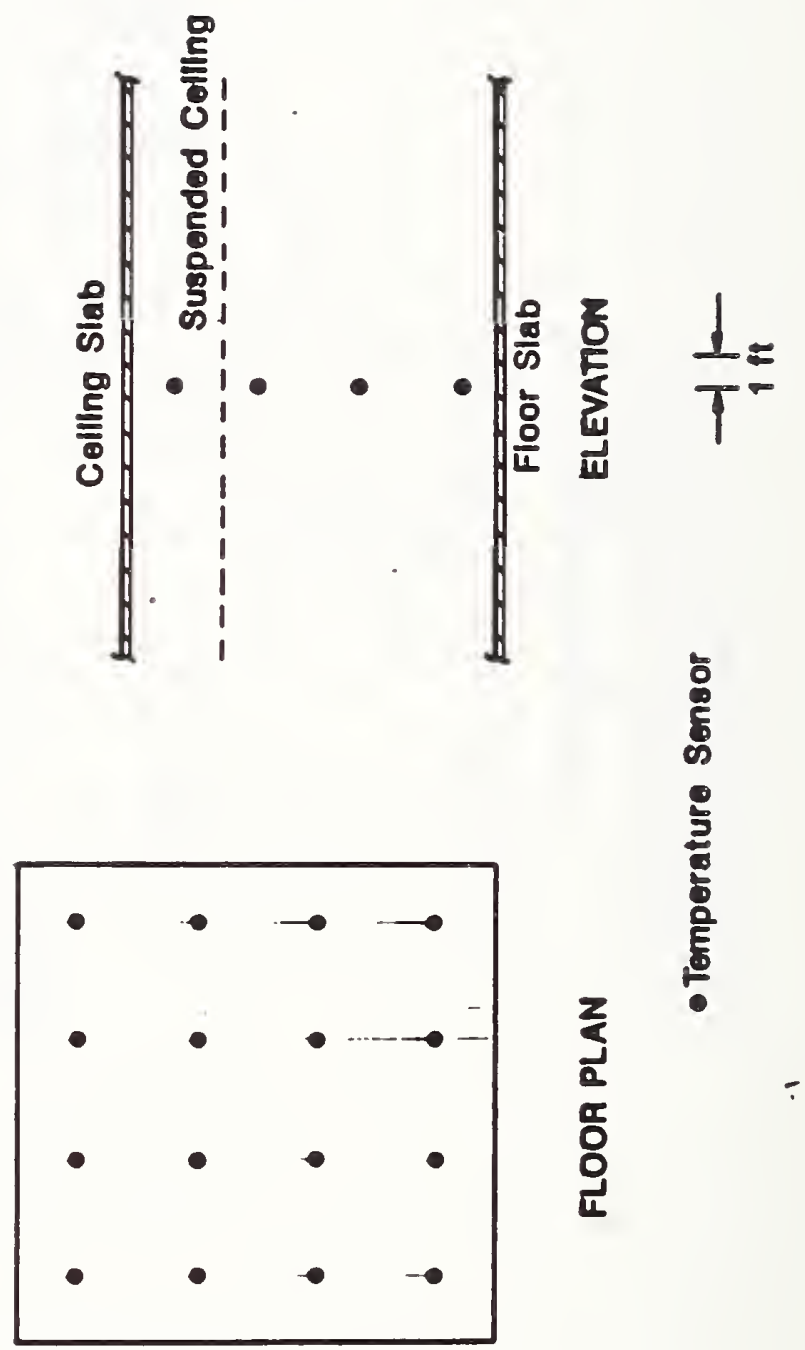

Figure 12. Alr temperature measurement locations 


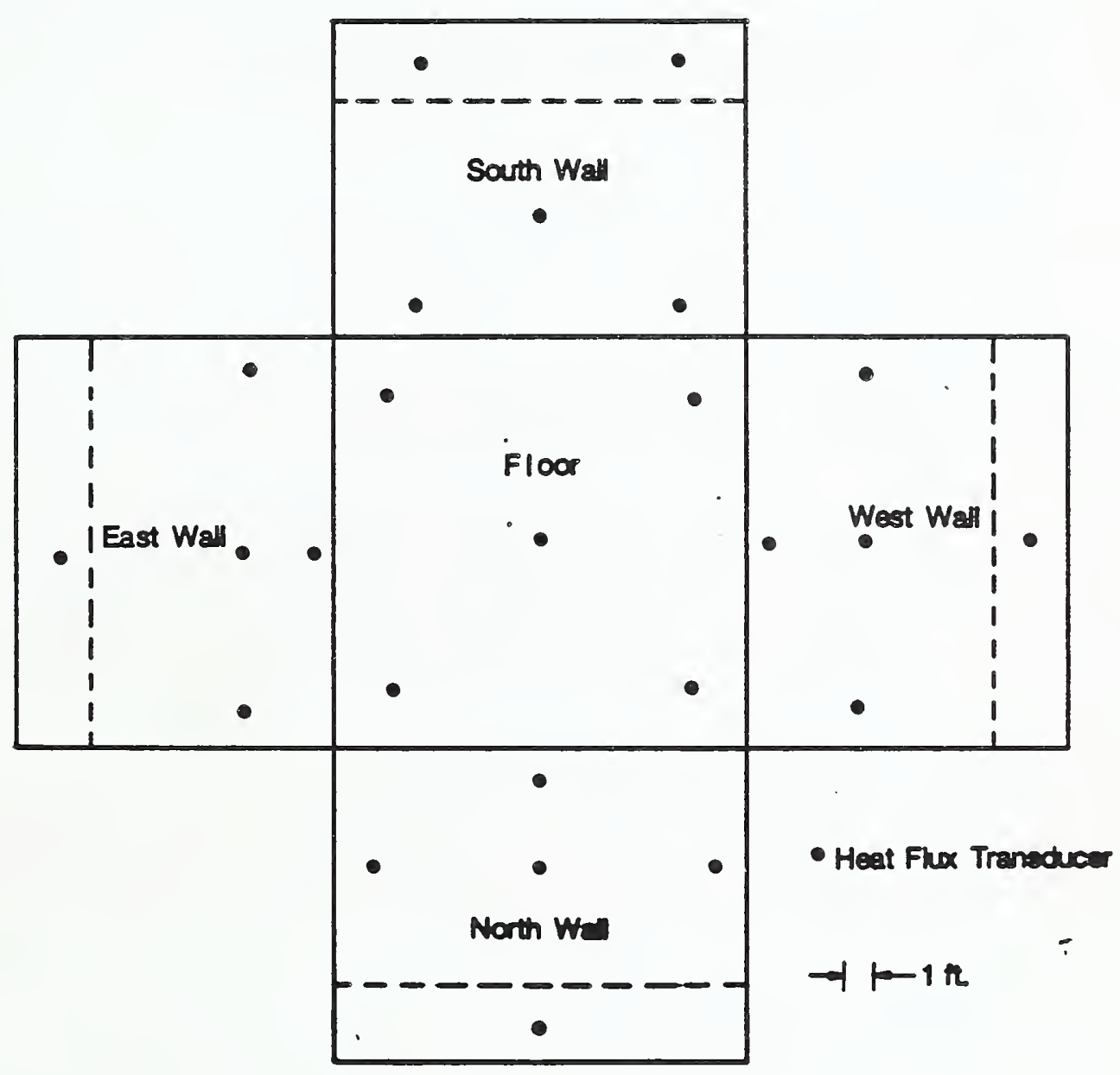

Figure 13. Locations of heat flux transducers 
NBS.114A (REV. 208C)

U.S. DEPT. OF COMM.

1. PUBLICATION OR

REPORT NO.

NBS I R $87-3656$

2. Performing Organ. Report Nof 3. Publication Date

BIBLIOGRAPHIC DATA

SHEET (See instructions)

4. TITLE AND SUBTITLE

Experimental Plan for Investigation of Lighting and HVAC Interactions

5. AUTHOR(S)

Stephen J. Treado

6. PERFORMING ORGANIZATION (If joint or other than NBS, see instructions)

7. Contract/Grant No.

MATIONAL BUREAU OF STANDARDS

DEPARTMENT OF COMMERCE

8. Type of Report \& Period Covered

WASHINGTON, D.C. 20234

9. SPOHSORING ORGANIZATION NAME AND COMPLETE AOCRESS (Street, Gity. Stote, ZIP)

National Bureau of Standards

Gaithersburg, MD 20899

10. SUPPLEMENTARY NOTES

Document describes a computer program; SF-185. FIPS Software Summary, is attached.

11. ABSTRACT (A 200-word or less factual summary of most significant information. If document includes a significant

bibliogrophy or literature survey. mention it here)

This report describes the experimental plan for the investigation of the interaction of lighting and HVAC systems, including the purpose and scope of the research, the test facility and instrumentation system, and the data collection and analysis procedures. The research focuses on the relationship between lighting system design and performance, room design, and HVAC system design for typical office-type construction.

A test facility will be constructed and instrumented to enable variation of lighting room and HVAC design. Testing will be performed for various configurations. The results will be used to develop design guidelines and modeling procedures, particularly for incorporation into building energy analysis computer programs.

12. KEY WORDS (Six to twelve entries: alphabetical order: capitalize only proper names; and separate key words by semicolons) building energy performance; cooling load; lighting; thermal performance; weighting factors

13. AVAILABILITY

X. Unlimited

For Official Distribution. Do Not Release to NTIS

Order From Superintendent of Documents, U.S. Government Printing Office, Washington, D.C. 20402.

F Order From National Technical Information Service (NTIS). Springfield. VA. 2216I
14. NO. OF

PRINTED PAGES

47

15. Price

$\$ 11.95$ 

